Bingham Linda (Orcid ID: 0000-0001-9104-1825)

\title{
Contact Allergy and Allergic Contact Dermatitis to Lavender: A Retrospective Study from an Australian Clinic
}

Linda J. Bingham, Mei M. Tam, Amanda M. Palmer, Jennifer L. Cahill, Rosemary L. Nixon

Skin and Cancer Foundation Inc, Occupational Dermatology Research and Education Centre, Carlton, Victoria, Australia

Keywords: Lavender, allergic contact dermatitis, sensitisation, patch test, essential oil, face eczema, hand eczema, hand dermatitis

\section{Corresponding author}

Dr Linda J Bingham, Skin and Cancer Foundation Inc., Level 1, 80 Drummond Street, Carlton 3053, Victoria, Australia. Tel: +61 39623 9400. Email: 1jbing@me.com

\section{Conflict of interest}

The authors have no conflicts of interest to declare.

This is the author manuscript accepted for publication and has undergone full peer review but has not been through the copyediting, typesetting, pagination and proofreading process, which may lead to differences between this version and the Version of Record. Please cite this article as doi: $10.1111 / \operatorname{cod} .13247$

This article is protected by copyright. All rights reserved. 


\begin{abstract}
Background: Lavender is commonly used in aromatherapy and in a broad range of personal and household products. It has been identified as a contact sensitizer and has been reported to cause allergic contact dermatitis (ACD).

Objectives: To report our experience with contact allergy and ACD to lavender and to raise awareness of lavender as a potential contact allergen.

Method: A retrospective database review was performed of patients attending patch testing clinics at the Skin and Cancer Foundation, Victoria, Australia, from January 1, 1993 to December 31, 2017.

Results: Among the 2178 patients patch tested to lavender over this period, a total of 58 positive reactions were recorded in 49 individuals, giving a positive patch test prevalence for patients tested to lavender of $2.2 \%$. Twenty-seven patients were diagnosed with ACD. The most common sources of exposure to lavender were personal care products and essential oils. Of the patients with ACD, 74\% were tested to lavender absolute with a positive result in $90 \%$ of cases.

Conclusion: Lavender is an uncommon cause of ACD but is important to consider given the potential for exposure through the use of personal care items and essential oils.
\end{abstract}

Keywords: Lavender; allergic contact dermatitis; sensitization; patch test; essential oil; face eczema; hand eczema; hand dermatitis 


\section{Introduction}

Lavender is the common name for the flowering plant species belonging to the genus Lavandula, a member of the Lamiaceae family. ${ }^{1}$ Since ancient times, lavender has been cultivated for use and it continues to have a wide range of modern applications. In Australia today, the commercial farming of lavender is a growth industry, with the production of lavender oil estimated to have a potential value of \$A3-5 million by $2025 .^{2}$ Lavender may be encountered in various forms including as fresh and dried flowers, as an essential oil and as plant derived extracts such as lavender absolute. It is a common constituent of perfumes, body care items, household products and food manufacture, as well as being widely utilised for aromatherapy and massage. ${ }^{1,3}$ Lavender has been investigated for potential therapeutic applications including as an antimicrobial, ${ }^{4,5}$ a pediculicide, ${ }^{6}$ an anxiolytic, ${ }^{7}$ an anti-inflammatory ${ }^{8}$ and as a topical agent to promote wound healing. 9,10

Lavender essential oil is acquired by the steam distillation of the flowering tops, with the type of oil produced dependent on the lavender species used. Lavender oil is distilled from Lavandula angustifolia, spike lavender oil from Lavandula latifolia and lavandin oil from cultivars of the hybrid Lavandula $x$ intermedia. ${ }^{11,12}$ In contrast, lavender absolute is manufactured from Lavandula angustifolia flowers by a process involving hexane and ethanol extraction. ${ }^{13}$ Whilst lavender absolute and the different types of lavender oil vary in their specific compositions, they share a common major constituent in linalool. With the exception of spike lavender oil, they also contain a significant component of linalyl acetate. ${ }^{14}$ (Bo Niklasson, 
personal communication, December 13, 2018). Both linalool and linalyl acetate have been identified as potent contact allergens, when oxidized to form compounds such as hydroperoxides. ${ }^{15-18}$

There are numerous case reports of $\mathrm{ACD}$ to lavender in the medical literature. Examples include facial dermatitis in 2 patients due to lavender oil applied to their pillows ${ }^{19}$ and a woman with vulvovaginitis exacerbated by a moisturiser containing lavender oil. ${ }^{20}$ The incorporation of lavender into topical anti-inflammatory gels has been identified as contributing to allergic reactions, including photoallergic contact dermatitis. ${ }^{21,22}$ Lavender is also recognised as an occupational sensitizer and the cause of ACD, particularly in masseurs and aromatherapists. ${ }^{23-26}$ The trend for aromatherapy with lavender oil and extensive use of dried lavender flowers has been suggested to explain a sudden increase in the frequency of positive patch tests to lavender in Japan. ${ }^{27}$ The widespread use of lavender and concerns about its propensity to cause contact allergy has seen lavender absolute $2 \%$ pet. added to the American Contact Dermatitis Society baseline series. ${ }^{28}$ Lavender exposure may go unreported, with patients potentially unaware that it can cause allergic contact dermatitis, instead perceiving essential oils to be "natural" and "safe". 29

\section{Patients and Methods}

A retrospective review was performed using a database of patients seen in the Contact Dermatitis and Occupational Dermatology clinics at the Skin and Cancer Foundation, Victoria, Australia 
from January 1, 1993 to December 31, 2017. Over this period 4 different lavender preparations were used for testing, lavender absolute $2 \%$ pet. (Chemotechnique Diagnostics, Vellinge, Sweden) as well as lavender oil $2 \%$ pet., spike lavender oil $8 \%$ pet. and lavandin oil $2 \%$ pet. The latter 3 preparations were obtained from a local compounding pharmacy. During this period, lavender absolute and lavender oil formed part of our 'Fragrance Rare' allergen series, whereas spike lavender oil and lavandin oil were included in our 'Other Essential Oils' series. The decision to test a patient to one or more lavender preparations was at the discretion of the consultant dermatologist. All patients were also patch tested with a modified European baseline series (prior to 2010) or thereafter the Australian Baseline series (ABS) ${ }^{30}$ with additional series based on exposures relevant to each patient. Patients were also patch tested to their own contactants, diluted where necessary. Allergens were sourced from Chemotechnique Diagnostics, Hermal (Reinbek, Germany) and allergEAZE by SmartPractice (Phoenix, Arizona).

Testing was performed with allergEAZE Patch Test Chambers (SmartPractice) or Finn Chambers (Epitest, Tuusula, Finland; now SmartPractice) on Scanpor tape (Norgesplaster, Vennesla, Norway). Patches were applied to the upper back for 2 days. Readings were performed on day 2 and day 4 according to ESCD guidelines. ${ }^{31}$ All reactions with a reading of + to +++ were included as positive reactions. The clinical relevance of a reaction was determined by the consultant dermatologist and was based on a presentation consistent with ACD, as well as temporal exposure to a lavender-containing preparation. 
Data was collected on patient age, gender, atopic background, co-existing diagnoses (including endogenous eczema, irritant dermatitis, contact urticaria/protein contact dermatitis, other dermatoses), site of dermatitis and the potential source of exposure, including whether this was occupationally related. The presence of other positive patch test results was also recorded, in particular testing to linalool. The only exclusion criterion was patients who had not consented for the use of their information for research purposes.

\section{Results}

During the study period, 9714 patients underwent patch testing. Of these 58 were excluded from further analysis as they did not give consent. Of the remaining 9656 patients, 2178 were patch tested to lavender, with the majority tested to more than one lavender preparation. A total of 1341 tests were performed to lavender absolute, 1917 to lavender oil, 180 to spike lavender oil and 169 to lavandin oil.

Collectively across the 4 lavender allergen preparations, there were a total of 58 positive reactions recorded, occurring in 49 people. This produced a positive patch test prevalence of $0.5 \%(49 / 9656)$ for all patients and 2.2\% (49/2178) for patients tested to lavender. Of the 58 positive reactions, 34 were deemed to be clinically relevant and occurred in 27 patients. Twentytwo patients were classified as having reactions of unknown relevance and 2 had reactions deemed to be of past relevance (Table 1). The 27 patients with ACD comprised 25 females (93\%) and 2 males (7\%). The mean patient age was 45 years (range 22-67 years). 
The majority of patients diagnosed with ACD to lavender were patch tested to lavender absolute $(20 / 27 ; 74 \%)$. Of those tested to lavender absolute, $90 \%$ recorded a positive reaction (18/20). All 18 patients positive on testing with lavender absolute were also tested to lavender oil. Correlation of positive reactions between these two preparations was low, with only $2 / 18$ (11\%) patients also reacting to lavender oil (patients 4, 24). Twelve patients diagnosed with ACD to lavender were tested to both spike lavender oil and lavandin oil. Spike lavender oil caused reactions in 12/12 (100\%) patients, whilst lavandin oil was only positive in 2/12 (17\%). The 12 patients with positive reactions to spike lavender oil included 7 patients who were not tested to lavender absolute. The remaining 5 cases were tested to lavender absolute with 2 patients recording negative outcomes (patients 4,17) and 3 patients (patients 7, 21, 26) producing positive test results.

In all except one case, the potential source of exposure was identified as either lavender oil or as a component of a perfume, skin care or washing product. The one exception was a woman exposed to lavender flowers in her garden. In all cases of ACD, there was a record of exposure to a lavender containing product in the patient's history. The results of patch testing to the suspected source items was available in 17 patients $(17 / 27 ; 63 \%)$, with a positive result obtained in 11 cases (Table 2). In 6 cases the reaction to the item was doubtful or negative. In the remaining 10 cases, the results of testing to the patients' own products were not available. This was due to either the item in question not being available at the time of testing or because specific details of the personal items tested were not recorded in the database. 
The potential relationship of lavender exposure to the patient's occupation was documented in 19/27 (70\%) of cases. Of these 19 cases, the majority $(17 / 19,89 \%)$ were assessed as not work related. Two cases were found to be connected to employment, with one an aromatherapist and the other a massage therapist. Both instances involved exposure to essential oils containing lavender. The most commonly involved body sites in lavender ACD were the hands and face, with 12 and 11 cases respectively (Table 2). Consultant assessment of diagnoses present in addition to ACD revealed atopy in 9 of the 27 cases (33\%), endogenous eczema in 4 $(15 \%)$ and irritant contact dermatitis in $3(11 \%)$. The majority of patients with ACD had positive patch tests results to other allergens in addition to lavender $(25 / 27 ; 93 \%)$. The three most frequent concomitant positive reactions were to fragrance mix I, fragrance mix II and Myroxylon pereriae resin (Table 3). Eighteen of the 27 patients were tested to linalool 10\% pet., with reactions in $2 / 18$ cases $(11 \%)$.

\section{Discussion}

We report 27 patients with ACD to lavender, with a total of 34 positive reactions from testing with 4 different lavender patch test preparations. Consistent with previous studies, most of the positive reactions occurred in females. ${ }^{15,27}$ In the majority of cases, exposure to lavender was linked to the use of lavender essential oil, personal care products containing lavender or a combination of both. The face and hands were the most common sites involved. This is compatible with the likely sites for skin contact to such items. Similar to the observation of Grey 
et al, ${ }^{29}$ it has anecdotally been our experience that some patients are surprised to learn that they can be allergic to lavender. In our series, 2 patients with ACD were exposed to lavender through their employment as aroma and massage therapists. Both of these occupations have previously been identified to be at risk of sensitisation to essential oils. Bleasel et $\mathrm{al}^{24}$ reported 3 cases of hand dermatitis linked to working in aromatherapy and the massage industry, with patients reacting to a range of botanicals, including lavender.

We found a positive patch test prevalence of $2.2 \%$ for patients tested to lavender. We acknowledge that our figure may be an underestimate of the true prevalence within this selected patient population due to the heterogenous nature of testing performed, with all patients not tested to each of the 4 lavender allergen preparations. Testing for lavender allergy is made more challenging by the range of lavender derived products available and their different chemical compositions. ${ }^{14}$ Clarifying the nature of an exposure is further complicated by the variable nomenclature used in product labelling. ${ }^{11}$ Over the period of this study, 4 different lavender allergen preparations were in use. The historical details of how this developed are unclear, however the basic rationale was to broaden the testing to reflect the diverse forms of potential lavender exposure.

Most individuals in our series were tested to more than one lavender preparation and this often produced both positive and negative reactions. Across the 4 preparations, patients were more frequently tested to lavender absolute and lavender oil. Relatively few patients were tested 
to spike lavender oil and lavandin oil. This may be partly explained by their location in different allergen series within our allergen bank.

It is acknowledged that comparing responses to different allergen preparations is limited by the variable pattern of testing, however it was found that patients tested to spike lavender oil showed a higher rate of positive reactions. In contrast, lavender oil produced very few positive results despite being tested in a relatively large number of patients. Many factors may have potentially contributed to the diversity of results we observed to different lavender preparations. One of these factors is the percentage of allergen employed in testing. Spike lavender oil was tested at a higher concentration of $8 \%$ pet., which may have increased the test sensitivity. Alternatively, it may potentially produce a higher rate of irritant reactions which, if misinterpreted, could generate more false positive outcomes. The converse argument can be made for lavender oil which was tested $2 \%$ pet. Some studies have employed higher concentrations, for example Hagvall et al used $6 \%$ pet. ${ }^{15}$ and it is possible that the lower concentration may have led to false negative results.

Another potentially significant influence on the patch test result obtained is the heterogeneity of the chemical composition of the different allergen preparations. A number of the main constituents are shared between the lavender allergens used, albeit in varying proportions ${ }^{14}$ (Bo Niklasson, personal communication, December 13, 2018). Linalool is present in all 4 allergens and 3 out of 4 also contain significant levels of linalyl acetate, with the exception spike lavender oil. Other major common constituents found in the 3 oils include 
camphor and 1,8-cineole. In contrast lavender absolute does not contain significant levels of the latter 2 chemicals but has high levels of coumarin. There are however a large number of other chemicals which have also been recorded and analysis of lavender derived oils have shown over 400 compounds may be present. ${ }^{32}$

In addition, the allergenic nature of the compounds present can be altered by the process of autoxidation. Formal studies examining the allergenicity of lavender oil in humans have produced variable results and it has been suggested that this can be explained by the effect of autoxidation, leading to the generation of more potent contact allergens. ${ }^{11}$ Both linalool and linalyl acetate are only weakly allergenic when present in their pure form, however autoxidation leads to the production of potent sensitizers, in particular hydroperoxides. ${ }^{15-18}$ It is thus advised that testing is performed with the oxidized forms of these chemicals.

With respect to the allergens used in our clinic, the 3 oil preparations were compounded through a local pharmacy and chemical analysis of their specific composition is not available. The oxidation state of the lavender allergens is also unknown. The preparations were not intentionally oxidised however it is possible that autoxidation may have occurred. Tests on lavender oil have shown that it lacks natural protection against autoxidation and that the sensitizing potency increases on air exposure. ${ }^{33}$ The International Fragrance Association recommends the addition of antioxidants to natural products know to be rich in linalool to reduce the formation of allergenic oxidation products. ${ }^{34}$ 
Identifying the allergenic component of essential oils is challenging and it is recognised that they are often unknown. ${ }^{12}$ The role of linalool and linalyl acetate in lavender oil allergy was investigated by Hagvall and Christensson ${ }^{15}$ who patch tested over 1600 patients to the oxidized forms of lavender oil, linalyl acetate and linalool. They found that $44 \%$ of the patients with positive reactions to oxidized lavender oil did not react to oxidized linalool or oxidized linalyl acetate. Explanations given for this result include increased allergenic potency due to a mixture of sensitizers or chemical reactions within the oxidised oil, leading to the formation of new compounds. A significant proportion of our cases with ACD to lavender were also tested to linalool, with a low number of positive reactions recorded. A further factor which may have influenced our results was the use of an unoxidized linalool preparation for the majority of the study period. An oxidised linalool preparation is now included in the ABS.

In addition to lavender, the majority of our patients had positive patch tests results to other allergens, in particular fragrance mixes I and II. Co-reactivity to fragrance mixes is a frequent finding in patients with contact allergy to essential oils and may be explained by pseudo cross-reactivity, genuine cross-reactivity and concomitant sensitization. ${ }^{35}$ Testing to specific essential oils is recommended as studies have shown that relying on the use of fragrance mixes may not detect all cases. ${ }^{36,37}$

It is beyond the scope of our study to recommend the best allergen preparations to use for lavender patch testing. In response to our findings we have simplified our regime to the use of lavender absolute 2\% pet. (Chemotechnique Diagnostics) and spike lavender oil 2\% 
pet. (supplied by a local compounding pharmacy as no commercial test preparation is available). These form part of our 'Fragrance Common' series. Where possible patients are also tested to their own products to assist in determining the relevance of test results. The concentration of spike lavender oil has been reduced to $2 \%$ pet., as it was noticed to be producing a number of strong positive reactions. This concentration is consistent with commercially available preparations for lavender absolute (Chemotechnique Diagnostics) and Lavandula angustifolia oil (SmartPractice, Calgary, Alberta, Canada) and is a common test concentration for other essential oils. ${ }^{38}$ Defining the most appropriate test concentration for spike lavender oil remains an area for further investigation.

\section{Conclusion}

We report a case series of $\mathrm{ACD}$ to lavender, in order to raise awareness of lavender as a possible cause of contact allergy. Common sources of patient exposure are lavender essential oils and body care products. Patch testing is recommended if a history of contact is identified. 


\section{References}

1. $\quad$ Wu PA, James WD. Lavender. Dermatitis. 2011;22:344-347.

2. Coriolis. New opportunities in new \& emerging agricultural industries in Australia. https://www.agrifutures.com.au/wp-content/uploads/2017/07/Coriolis-Scan_new-andemerging-industries.pdf. Published December 2017. Accessed September 19, 2018.

3. De Groot A, Schmidt E. Essential oils, part v: peppermint oil, lavender oil, and lemongrass oil. Dermatitis. 2016;27:325-332.

4. Sienkiewicz M, Lysakowska M, Kowalczyk E, et al. The ability of selected plant essential oils to enhance the action of recommended antibiotics against pathogenic wound bacteria. Burns. 2017;43:310-317.

5. Bona E, Cantamessa S, Pavan M, et al. Sensitivity of candida albicans to essential oils: are they an alternative to antifungal agents? J Appl Microbiol. 2016;121:1530-1545.

6. Barker SC, Altman PM. An ex vivo, assessor blind, randomised, parallel group, comparative efficacy trial of the ovicidal activity of three pediculicides after a single application--melaleuca oil and lavender oil, eucalyptus oil and lemon tea tree oil, and a "suffocation" pediculicide. BMC Dermatol. 2011;11:14.

7. Franco L, Blanck TJ, Dugan K, et al. Both lavender fleur oil and unscented oil aromatherapy reduce preoperative anxiety in breast surgery patients: a randomized trial. $J$ Clin Anesth. 2016;33:243-249.

This article is protected by copyright. All rights reserved. 
8. Cardia GFE, Silva-Filho SE, Silva EL, et al. Effect of lavender (lavandula angustifolia) essential oil on acute inflammatory response. Evid Based Complement Alternat Med. 2018;2018:10.

9. Marzouk T, Barakat R, Ragab A, Badria F, Badawy A. Lavender-thymol as a new topical aromatherapy preparation for episiotomy: a randomised clinical trial. J Obstet Gynaecol. 2015;35:472-475.

10. Mori HM, Kawanami H, Kawahata H, Aoki M. Wound healing potential of lavender oil by acceleration of granulation and wound contraction through induction of TGF-beta in a rat model. BMC Complement Altern Med. 2016;16:144.

11. Gangemi S, Minciullo PL, Miroddi M, Chinou I, Calapai G, Schmidt RJ. Contact dermatitis as an adverse reaction to some topically used European herbal medicinal products-part 2: echinacea purpurea-Lavandula angustifolia. Contact Dermatitis. 2015;72:193-205.

12. de Groot AC, Schmidt E. Essential oils, Part I: Introduction. Dermatitis. 2016;27:39-42.

13. Chemotechnique Diagnositics. Patch Test Products Lavender Absolute. https://www.chemotechnique.se/products/haptens/lavandula-angustifolia-oil/. Accessed December 11, 2018.

14. de Groot AC, Schmidt E. Essential Oils Contact Allergy and Chemical Composition. Boca Raton, FL: CRC Press; 2016.

This article is protected by copyright. All rights reserved. 
15. Hagvall L, Christensson JB. Patch testing with main sensitizers does not detect all cases of contact allergy to oxidized lavender oil. Acta Derm Venereol. 2016;96:679-683.

16. Audrain H, Kenward C, Lovell CR, et al. Allergy to oxidized limonene and linalool is frequent in the U.K. Br J Dermatol. 2014;171:292-297.

17. Skold M, Hagvall L, Karlberg AT. Autoxidation of linalyl acetate, the main component of lavender oil, creates potent contact allergens. Contact Dermatitis. 2008;58:9-14.

18. Skold M, Börje A, Matura M, Karlberg AT. Studies on the autoxidation and sensitizing capacity of the fragrance chemical linalool, identifying a linalool hydroperoxide. Contact Dermatitis. 2002;46:267-272.

19. Coulson IH, Ali Khan AS. Facial "pillow" dermatitis due to lavender oil allergy. Contact Dermatitis. 1999;41:111.

20. Varma S, Blackford S, Statham BN, Blackwell A. Combined contact allergy to tea tree oil and lavender oil complicating chronic vulvovaginitis. Contact Dermatitis. 2000;42:309-310.

21. Goiriz R, Delgado-Jimenez Y, Sanchez-Perez J, Garcia-Diez A. Photoallergic contact dermatitis from lavender oil in topical ketoprofen. Contact Dermatitis. 2007;57:381-382.

22. Rademaker M. Allergic contact dermatitis from lavender fragrance in difflam gel. Contact Dermatitis. 1994;31:58-59.

23. Trattner A, David M, Lazarov A. Occupational contact dermatitis due to essential oils. Contact Dermatitis. 2008;58:282-284. 
24. Bleasel N, Tate B, Rademaker M. Allergic contact dermatitis following exposure to essential oils. Aus J Dermatol. 2002;43:211-213.

25. Keane FM, Smith HR, White IR, Rycroft RJ. Occupational allergic contact dermatitis in two aromatherapists. Contact Dermatitis. 2000;43:49-51.

26. Cockayne SE, Gawkrodger DJ. Occupational contact dermatitis in an aromatherapist. Contact Dermatitis. 1997;37:306-307.

27. Sugiura M, Hayakawa R, Kato Y, Sugiura K, Hashimoto R. Results of patch testing with lavender oil in Japan. Contact Dermatitis. 2000;43:157-160.

28. Schalock PC, Dunnick CA, Nedorost S, Brod B, Warshaw E, Mowad C. American contact dermatitis society core allergen series: 2017 update. Dermatitis. 2017;28:141143.

29. Grey KR, Hagen SL, Warshaw EM. Essential oils: emerging "medicaments". Dermatitis. 2016;27:227-228.

30. Toholka R, Wang YS, Tate B, et al. The first Australian baseline series: recommendations for patch testing in suspected contact dermatitis. Aus J Dermatol. 2015;56:107-115.

31. Johansen JD, Aalto-Korte K, Agner T, et al. European society of contact dermatitis guideline for diagnostic patch testing-recommendations on best practice. Contact Dermatitis. 2015;73:195-221.

This article is protected by copyright. All rights reserved. 
32. de Groot AC, Schmidt E. Essential oils, Part III: Chemical composition. Dermatitis. 2016;27:161-169.

33. Hagvall L, Skold M, Brared-Christensson J, Börje A, Karlberg AT. Lavender oil lacks natural protection against autoxidation, forming strong contact allergens on air exposure. Contact Dermatitis. 2008;59:143-150.

34. International Fragrance Association (IFRA). $38^{\text {th }}$ Amendment. IFRA Standard (October 14, 2009) on Linalool CAS \#.: 78-70-6/126-90-9 (d-linalool)/126-91-0 (1-linalool). Available at: http://www.ifraorg.org/view_document.aspx?docId=23222. Accessed October 22, 2018.

35. de Groot AC, Schmidt E. Essential Oils, Part IV: Contact Allergy. Dermatitis. 2016;27:170-175.

36. Sabroe RA, Holden CR, Gawkrodger DJ. Contact allergy to essential oils cannot always be predicted from allergy to fragrance markers in the baseline series. Contact Dermatitis. 2016;74:236-241.

37. Warshaw EM, Zug KA, Belsito DV, et al. Positive patch-test reactions to essential oils in consecutive patients from North America and Central Europe. Dermatitis. 2017;28:246252.

38. SmartPractice Canada. Allergens / Perfumes/Flavors. https://www.smartpracticecanada.com/shop/wa/style?id=SCSERIESPFNA. Accessed December 21, 2018.

This article is protected by copyright. All rights reserved. 


\section{Tables}

Table 1. Summary of positive test results to 4 lavender patch test preparations

\begin{tabular}{|c|c|c|c|c|}
\hline Lavender allergen preparation & $\begin{array}{c}\text { Lavender absolute } \\
\mathbf{2 \%}\end{array}$ & $\begin{array}{c}\text { Lavender oil } \\
\mathbf{2 \%}\end{array}$ & $\begin{array}{c}\text { Lavender Spike Oil } \\
\mathbf{8 \%}\end{array}$ & $\begin{array}{c}\text { Lavandin oil } \\
\mathbf{2 \%}\end{array}$ \\
\hline Total number of positive reactions & 33 & 7 & 16 & 2 \\
\hline Relevant & 18 & 2 & 12 & 2 \\
\hline Unknown relevance & 13 & 5 & 4 & 0 \\
\hline Past relevance & 2 & 0 & 0 & 0 \\
\hline Number tested to preparation & 1341 & 1917 & $8.9 \%$ & 169 \\
\hline Percentage of positive reactions & $2.5 \%$ & $0.4 \%$ & & $1.2 \%$ \\
\hline
\end{tabular}


Table 2. Summary of clinically relevant positive patient patch test results to lavender

\begin{tabular}{|c|c|c|c|c|c|c|c|}
\hline \multirow{2}{*}{$\begin{array}{l}\text { Patient } \\
\text { Number }\end{array}$} & \multirow{2}{*}{$\begin{array}{l}\text { Age } \\
\text { Sex }\end{array}$} & \multirow{2}{*}{$\begin{array}{l}\text { Sites } \\
\text { involved }\end{array}$} & \multicolumn{4}{|c|}{ LAVENDER ALLERGEN(S) TESTED AND RESULT $^{\dagger}$} & \multirow[t]{2}{*}{ Lavender source (Patch test result) $^{\mathrm{TT}}$} \\
\hline & & & LAbs $2 \%$ & LOil $2 \%$ & LSpike 8\% & L-in $2 \%$ & \\
\hline 1 & $\begin{array}{l}22 \\
F\end{array}$ & $\begin{array}{l}\text { Neck } \\
\text { Chest } \\
\text { Back } \\
\text { Abdomen }\end{array}$ & + & - & NT & NT & $\begin{array}{l}\text { Shampoo \& conditioner (-) } \\
\text { Clinique facial treatment }(-)\end{array}$ \\
\hline 2 & $\begin{array}{l}23 \\
\mathrm{M}\end{array}$ & Hands & ++ & - & NT & NT & Massage oil (NA) \\
\hline 3 & $\begin{array}{l}23 \\
F\end{array}$ & $\begin{array}{l}\text { Hands } \\
\text { Face } \\
\text { Eyelids }\end{array}$ & + & - & NT & NT & Perfumed products (-) \\
\hline 4 & $\begin{array}{l}30 \\
\mathrm{~F}\end{array}$ & Hands & - & + & + & - & $\begin{array}{l}\text { Easy Air vapour stick (+) } \\
\text { Lavender essential oil }(+) \\
\text { Sukin Shampoo with lavender (NA) }\end{array}$ \\
\hline 5 & $\begin{array}{l}33 \\
\mathrm{~F}\end{array}$ & $\begin{array}{l}\text { Face } \\
\text { Neck }\end{array}$ & NT & NT & ++ & + & $\begin{array}{l}\text { Verage serum }(++) \\
\text { Past tense tension blend essential oil }(++)\end{array}$ \\
\hline 6 & $\begin{array}{l}37 \\
\mathrm{~F}\end{array}$ & Face & + & - & & NT & Jurlique moisturizer $(+)$ \\
\hline 7 & $\begin{array}{l}37 \\
F\end{array}$ & $\begin{array}{l}\text { Hands } \\
\text { Face }\end{array}$ & + & - & + & - & Lavender spa oil $(+)$ \\
\hline 8 & $\begin{array}{l}40 \\
\mathrm{~F}\end{array}$ & Hands & + & - & NT & NT & Massage oil (NA) \\
\hline 9 & $\begin{array}{l}40 \\
\mathrm{~F}\end{array}$ & Arms & NT & NT & + & - & Natural Instinct body wash (+/-) \\
\hline 10 & $\begin{array}{l}41 \\
F\end{array}$ & $\begin{array}{l}\text { Hands } \\
\text { Arms }\end{array}$ & + & - & NT & NT & Massage oil (NA) \\
\hline 11 & $\begin{array}{l}41 \\
\mathrm{~F}\end{array}$ & Face & NT & NT & + & - & Chantecaille cream (NA) \\
\hline 12 & $\begin{array}{l}42 \\
F\end{array}$ & $\begin{array}{l}\text { Chest } \\
\text { Hands } \\
\text { Face }\end{array}$ & + & - & NT & NT & Lavender in garden (NA) \\
\hline 13 & $\begin{array}{l}43 \\
F\end{array}$ & Hands & + & - & NT & NT & Massage oil with lavender (NA) \\
\hline 14 & $\begin{array}{l}46 \\
\mathrm{~F}\end{array}$ & Arms & NT & NT & ++ & - & Essential oils containing lavender $(++)$ \\
\hline 15 & $\begin{array}{l}46 \\
F\end{array}$ & $\begin{array}{l}\text { Face } \\
\text { Eyelids } \\
\text { Neck }\end{array}$ & + & - & NT & NT & $\begin{array}{l}\text { Fragranced products (NA) } \\
\text { Lavender scented wash powder (NA) }\end{array}$ \\
\hline 16 & $\begin{array}{l}47 \\
M\end{array}$ & $\begin{array}{l}\text { Hands } \\
\text { Eyelids }\end{array}$ & + & - & NT & NT & Essential oils for massage \& aromatherapy (NA) \\
\hline 17 & $\begin{array}{l}48 \\
F\end{array}$ & Oral & - & - & + & - & $\begin{array}{l}\text { Toothpaste containing essential oils (-) } \\
\text { Shampoo (-) } \\
\text { Moisturiser (-) }\end{array}$ \\
\hline 18 & $\begin{array}{l}48 \\
F\end{array}$ & $\begin{array}{l}\text { Neck } \\
\text { Arms } \\
\text { Legs }\end{array}$ & NT & NT & + & $+/-$ & Massage oil $(+)$ \\
\hline 19 & $\begin{array}{l}51 \\
F\end{array}$ & Hands & NT & NT & + & - & Essential oil aromatherapy (+) \\
\hline 20 & $\begin{array}{l}52 \\
F\end{array}$ & $\begin{array}{l}\text { Face } \\
\text { Arms }\end{array}$ & + & - & NT & NT & $\begin{array}{l}\text { Jojoba night cream }(+) \\
\text { Jojoba hydrating day cream }(+) \\
\text { Lavender oil }(+/-)\end{array}$ \\
\hline 21 & $\begin{array}{l}56 \\
F\end{array}$ & Eyelids & + & - & + & + & Lavender hand cream (+) \\
\hline 22 & $\begin{array}{l}56 \\
\mathrm{~F}\end{array}$ & $\begin{array}{l}\text { Hands } \\
\text { Arms }\end{array}$ & + & NT & NT & NT & Lavender \& rose massage oil (+/-) \\
\hline 23 & $\begin{array}{l}56 \\
\mathrm{~F}\end{array}$ & $\begin{array}{l}\text { Face } \\
\text { Eyelids }\end{array}$ & NT & NT & + & - & Aromatherapy wand used around face/neck (NA) \\
\hline
\end{tabular}




\begin{tabular}{|c|l|l|c|c|c|c|l|}
\hline 24 & $\begin{array}{l}59 \\
\text { F }\end{array}$ & Hands & + & + & NT & NT & L'occitane hand cream (-) \\
\hline 25 & $\begin{array}{l}62 \\
\text { F }\end{array}$ & Face & + & - & NT & NT & $\begin{array}{l}\text { Pure Elements face mask (+) } \\
\text { Pure Elements Shampoo (+) }\end{array}$ \\
\hline 26 & $\begin{array}{l}64 \\
\text { F }\end{array}$ & Face & + & - & ++ & - & Estee Lauder Conditioning lotion with lavender (+) \\
\hline 27 & $\begin{array}{l}67 \\
\text { F }\end{array}$ & $\begin{array}{l}\text { Neck } \\
\text { Arms } \\
\text { Chest } \\
\text { Feet }\end{array}$ & + & - & NT & NT & Lavender oil (NA) \\
\hline
\end{tabular}

${ }^{\dagger}$ LAbs = Lavender absolute; LOil= Lavender oil; LSpike = Spike lavender oil; L-in= Lavandin

oil

$\mathrm{F}=$ Female $\quad \mathrm{M}=$ Male

$\mathrm{NT}=$ not tested

+NA - not available 
Table 3. Concomitant positive patch test results in patients testing positive on lavender patch test

\begin{tabular}{|c|c|}
\hline ALLERGEN & NUMBER OF CASES \\
\hline Fragrance mix I & 15 \\
\hline Fragrance mix II & 11 \\
\hline Myroxylon pereirae (balsam of Peru) resin & 9 \\
\hline Citral; Ylang-ylang oil & 8 \\
\hline Geraniol & 6 \\
\hline Cananga oil; Geranium oil; Lemongrass oil; Nickel sulfate; & 5 \\
\hline $\begin{array}{l}\text { Citronellol; Colophonium; Dermatophagoides pteronyssinus /farinae mix; Hydroabietyl } \\
\text { alcohol; Tea tree oil }\end{array}$ & 4 \\
\hline Isoeugenol; Neroli oil; Peppermint oil; Rose oil; Sandalwood oil & 3 \\
\hline $\begin{array}{l}\text { Cedarwood oil; Cinnamyl alcohol; Compositae mix II; Eugenol; Formaldehyde; } \\
\text { Hydroxycitronellal; Iodopropynyl butylcarbamate; Laurel leaf oil; Lemon oil; Linalool; } \\
\text { Methylisothiazolinone; Sandela; Spearmint oil }\end{array}$ & 2 \\
\hline $\begin{array}{l}\text { 4-Aminoazobenzene; Anise alcohol; Benzoin tincture; Benzyl benzoate; Benzyl salicylate; } \\
\text { Butylphenyl methylpropional; Citronella oil; Cobalt chloride; Cocamidopropyl betaine; } \\
\text { Diazolidinyl urea; Disperse orange 3; DMDM hydantoin; Dodecyl gallate; Farnesol; } \\
\text { Galbanum resin oil; Hexyl cinnamal; Hydroxyisohexyl 3-cyclohexene carboxaldehyde; } \\
\text { Jasminum flower extract; Lanolin; Limonene; Methyisothiazolinone+ } \\
\text { Methychloroisothiazolinone; Narcissus poeticus flower extract; Phenyl salicylate; Potassium } \\
\text { dichromate; Powdered Nutmeg; Sesquiterpene lactone mix; Tanacetum parthenium } \\
\text { (feverfew) extract; Tanacetum vulgare extract; Taraxacum officinale extract; Wood mix }\end{array}$ & 1 \\
\hline
\end{tabular}




\section{University Library}

\section{- M M N E R VA A gateway to Melbourne's research publications}

Minerva Access is the Institutional Repository of The University of Melbourne

Author/s:

Bingham, LJ;Tam, MM;Palmer, AM;Cahill, JL;Nixon, RL

Title:

Contact allergy and allergic contact dermatitis caused by lavender: A retrospective study from an Australian clinic

Date:

2019-07-01

Citation:

Bingham, L. J., Tam, M. M., Palmer, A. M., Cahill, J. L. \& Nixon, R. L. (2019). Contact allergy and allergic contact dermatitis caused by lavender: A retrospective study from an Australian clinic. CONTACT DERMATITIS, 81 (1), pp.37-42. https://doi.org/10.1111/cod.13247.

Persistent Link:

http://hdl.handle.net/11343/285754 